\title{
CORRESPONDENCE
}

\section{A NEW SOIL TESTING APPARATUS}

(Ko, H. \& Scotr, R. F., Géotechnique 17, No. 1, 40-57)

Green (1967) has effectively stated the case regarding certain serious deficiencies of the Authors' new soil test box. Ko and Scott mention that small volumes of the sample at the corners and along the edges of the box may not be in a homogeneous stress state but did not consider this to be important. This would appear to represent simply an error in judgement. The Writer agrees with Green (1967) that the soil cube was appreciably restrained by the relatively stiff stainless steel spacing frame. The Authors offer insufficient evidence to support the conclusion that the stress state generated in the sample contained within the new soil test box was found to be uniform or the opinion that the present equipment measures the true deformational behaviour of the soil tested. The opinions of Green (1967) and those of the Writer can easily be verified analytically or through the performance of simple experiments.

The following brief and approximate analysis based on the theory of elasticity analytically demonstrates the possible importance of edge restraint for a particular stress path and a cylindrical specimen. Fig. 1(a) represents a free cylinder with homogeneous triaxial compression while Fig. 1(b) represents the same cylinder subjected to identical vertical loads but laterally fixed at four vertical edges.
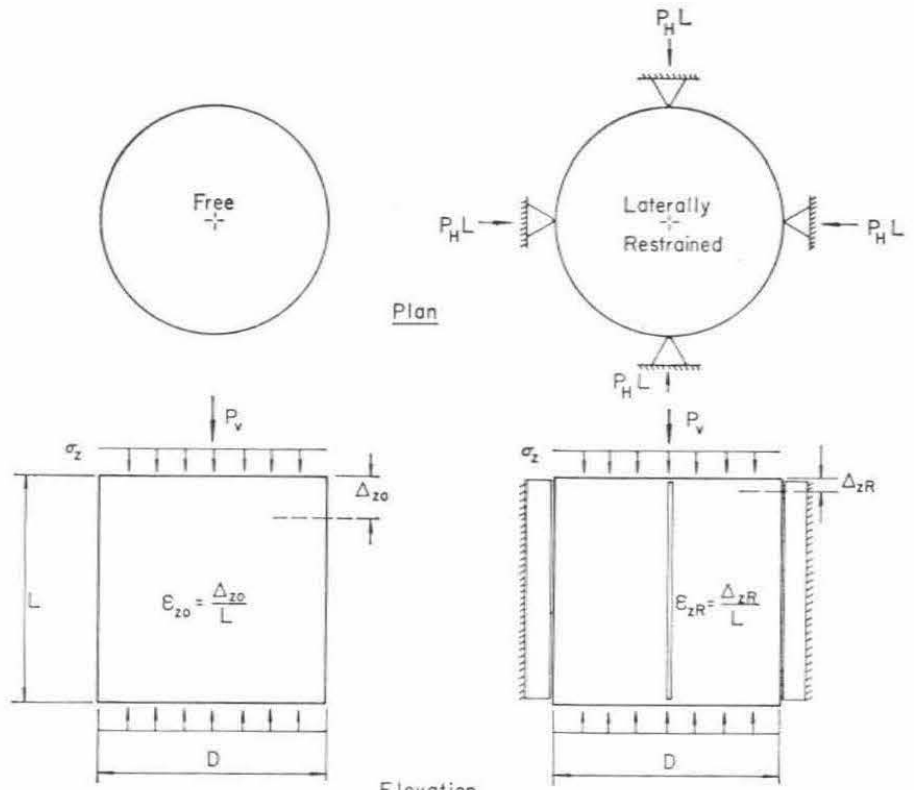

(a)

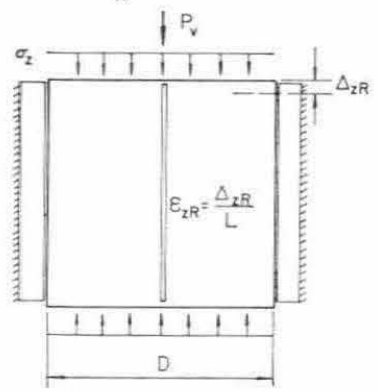

(b)

Fig. 1. Free and laterally restrained cylinders subjected to vertical loads 


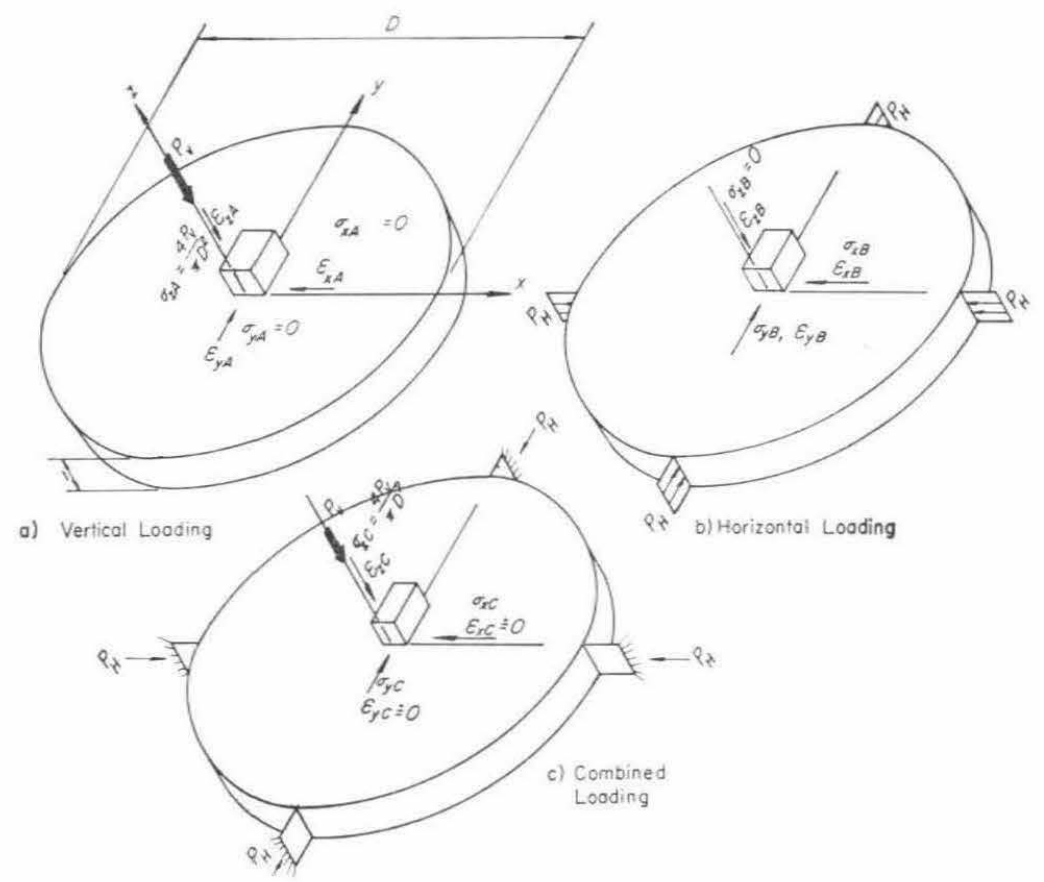

Fig. 2. Superposition of stress and strain for a laterally restrained disc

The ratio of the axial strains from the restrained to the homogeneous case $\epsilon_{z \mathrm{R}} / \epsilon_{z 0}$ represents a measure of the error involved due to the restraints. The solution to the homogeneous case is well known and is given by

$$
\epsilon_{z 0}=\frac{\sigma_{z}}{E}=\frac{4 P_{\mathrm{v}}}{\pi D^{2} E}
$$

where $P_{\mathrm{v}}$ represents the vertical load, $D$ represents the diameter of the cylinder and $E$ represents the modulus of elasticity. The solution to the restrained case may be obtained approximately by superposition of conditions for a central element (Fig. 2). The compressive strains for Fig. 2(a) are

and

$$
\epsilon_{z \mathrm{~A}}=\frac{4 P_{\mathrm{v}}}{\pi D^{2} E} \quad \cdot \quad \cdot \quad \cdot \quad . \quad . \quad . \quad . \quad . \quad .
$$

$$
\epsilon_{x \mathrm{~A}}=\epsilon_{y \mathrm{~A}}=-\nu \epsilon_{z \mathrm{~A}}=-\frac{4 \nu P_{\mathrm{v}}}{\pi D^{2} E}
$$

while those for Fig. 2(b) are

$$
\epsilon_{z \mathrm{~B}}=-\frac{\nu}{E}\left(\sigma_{x \mathrm{~B}}+\sigma_{y \mathrm{~B}}\right)=-\frac{2 \nu \sigma_{x \mathrm{~B}}}{E} \quad . \quad . \quad . \quad . \quad .
$$

and

$$
\epsilon_{x \mathrm{~B}}=\epsilon_{y \mathrm{~B}}=\frac{1}{E}\left(\sigma_{x \mathrm{~B}}-\nu \sigma_{y \mathrm{~B}}\right)=\frac{(1-\nu) \sigma_{x \mathrm{~B}}}{E} \quad . \quad . \quad . \quad .
$$

where $v$ represents Poisson's ratio. The solution for stresses at the axis of a circular disc 
according to Timoshenko and Goodier (1951) for the loading of Fig. 2(b) is represented by

$$
\sigma_{x \mathrm{~B}}=\sigma_{y \mathrm{~B}}=\frac{6 P_{\mathrm{H}}}{\pi D}
$$

where $P_{H}$ is the lateral restraint force per unit height. For the combined case, Fig. 2(c), the resulting principal horizontal strains along the $x$ and $y$ axis vary, but the average value is zero because points at the origin and at the boundary are laterally fixed. Upon substitution of equation (6) into equation (5) and assuming for $x=0$ that $\epsilon_{x \mathrm{C}}=\epsilon_{x \mathrm{~A}}+\epsilon_{x \mathrm{~B}}=0$ and $\epsilon_{y \mathrm{C}}=\epsilon_{y \mathrm{~A}}+\epsilon_{y \mathrm{~B}}=0$, the following expression is obtained:

$$
P_{\mathrm{H}}=\frac{2}{3}\left(\frac{\nu}{1-\nu}\right) \frac{P_{\mathrm{v}}}{D}
$$

The axial strain for the restrained case, Fig. 2(c), is given by

$$
\epsilon_{z \mathrm{C}}=\epsilon_{z \mathrm{~A}}+\epsilon_{z \mathrm{~B}}=\frac{4 P_{\mathrm{v}}}{\pi D^{2} E}\left[\frac{(1-2 \nu)(1+\nu)}{(1-\nu)}\right] \quad . \quad . \quad . \quad .
$$

and the axial strain ratio for the restrained versus the free case is given by

$$
\frac{\epsilon_{z \mathrm{R}}}{\epsilon_{z 0}}=\frac{\epsilon_{z \mathrm{C}}}{\epsilon_{z 0}}=\frac{(1-2 \nu)(1+\nu)}{(1-\nu)}
$$

A similar analysis was carried out for other elements along the $x$ axis which resulted in the conclusion that surfaces originally orthogonal to the axis of the restrained cylinder will warp. At a representative distance from the axis of the cylinder, $x=D / 3$, the axial strain ratio was found to be

$$
\frac{\epsilon_{z \mathrm{R}}}{\epsilon_{z 0}}=\left[1-\left(\frac{\nu^{2}}{1 \cdot 015+0 \cdot 015 \nu}\right)\right]
$$

The calculations required to obtain equation (10) are lengthy and are not presented here.

According to the foregoing analysis if Poisson's ratio is zero and horizontal expansion does not occur, then the axial strain ratio is unity and the restrained solution is accurate in accordance with physical reasoning. For the case of constant volume where Poisson's ratio is $0 \cdot \mathbf{5}$, the axial strain ratio is 0.76 according to equation (10) and the associated error is $24 \%$. The error involved with the restraints is seen to increase with the tendency of the material to expand laterally.

It is recognized that the Authors dealt specifically with a sand cube with a square cross section and that an approximate theory of elasticity for a cylinder does not represent well the non-linear, non-elastic behaviour of any soil. Several triaxial compression tests were performed by the Writer and Clarence T. Y. Fung at Colorado State University to demonstrate more clearly the importance of edge restraint in the Authors' apparatus.

The triaxial tests reported here were performed on 4 inch Ottawa sand cubes confined under a vacuum of 24 inches of mercury in a thin rubber membrane. As nearly as possible, the medium dense samples were formed identically by dropping sand from a height of 30 inches into the same membrane held in a cubic vacuum mould. A thin rubber sheet was cemented in place to form the top prior to the application of vacuum. The only variable considered was the presence or lack of 4 vertical edge restraints in the shear test (Fig. 3). An Instron testing machine automatically recorded loads and displacements with the rate of axial deformation set at $0.02 \mathrm{in} . / \mathrm{min}$. The lateral deformations were measured with a caliper periodically at midheight for the free specimens. The results of two tests are shown in Fig. 4. The data were considered unreliable below $0.2 \%$ axial strain and somewhat in error below $1.0 \%$ strain. A comparison of the axial strains for the free versus the restrained specimen clearly indicates the rôle played by the restraints. The axial strain ratio appears to decrease with shearing distortion to approximately 0.4 at the peak point for the free specimens. The overall behaviour 


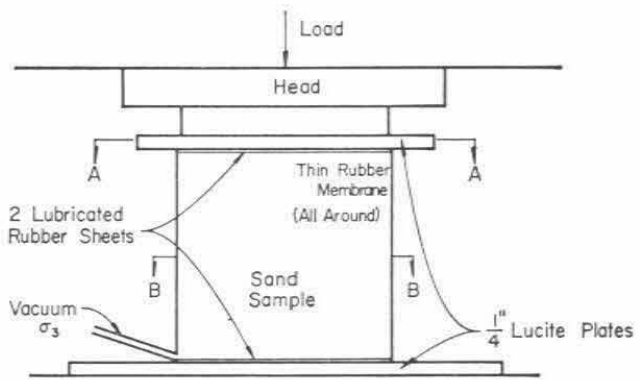

Elevation

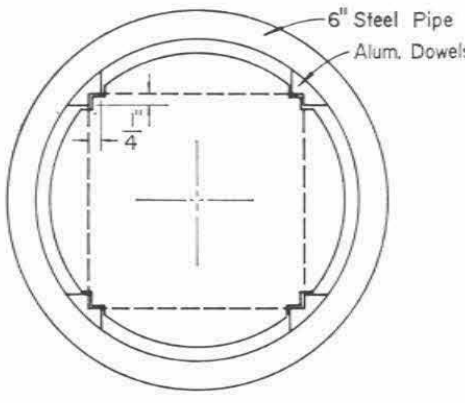

Section A-A

Specimen With Lateral

Restraints

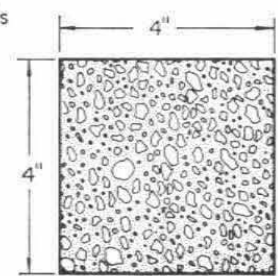

Section B-B

Specimen Without Lateral Restraints
Fig. 3. Free and laterally restrained test apparatus
Fig. 4. Comparison of test results for free and laterally restrained cubic medium dense Ottawa sand specimens

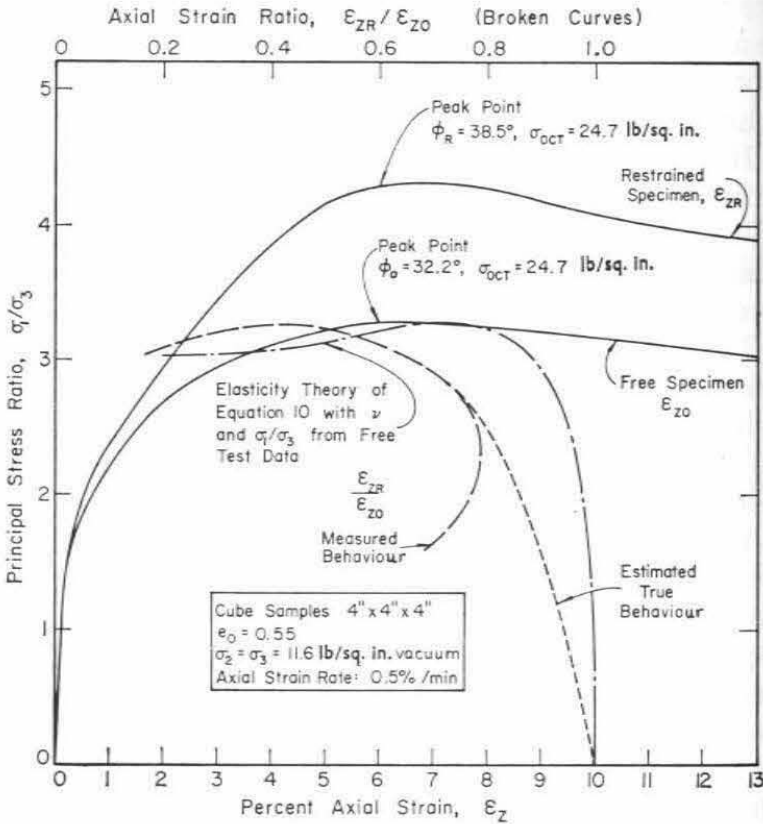


(Fig. 4), is qualitatively in accordance with that indicated by the previous approximate elastic analysis and equation (10).

The six faces of all test samples in the main remained nearly plane and orthogonal through yield but the restrained specimens were seriously distorted in a zone extending from $0-\frac{1}{4}$ inch from the aluminium dowels (Fig. 3). Edge restraint would appear to have been much more serious in the triaxial tests described by Ko and Scott (see Authors' Fig. 13, Test TC a-1) where twelve edges of the sand sample were in physical contact with the stainless steel spacing frame. Tests of the type reported here require no complex equipment, are easily performed and take about 45 minutes to carry out.

Kjellman (1936) first emphasized the importance of maintaining homogeneous stress or strain in obtaining true mechanical properties of soils from physical tests. The effect of the intermediate principal stress on the yielding of real granular materials has been of major practical importance for some time but still remains to be conclusively decided. The Writer is of the opinion that although it is not possible to construct a general stress-strain apparatus for soils which will completely satisfy those ideal conditions which are desired, further attempts must be made to improve existing apparatus and develop new tools to investigate the true physical behaviour of soils under load.

The various types of apparatus developed must yield the same physical parameters regardless of sample size or shape for similar stress or strain paths before the quality of any particular apparatus can be practically insured. In this light, improved models of existing special purpose apparatus still may well have a useful purpose in stress-strain and strength research. The value of the more common shear tests will also be increased by better interpretations made possible because of an improved knowledge of true soil behaviour. In addition, it is thought that if a general stress or strain controlled apparatus is ever to have widespread application then it must be simple in operation for a wide range of materials. It would appear that a considerable amount of research remains to be carried out before these important goals are achieved. The Authors did state clearly why stress-strain relationships should now be of increased practical importance.

\section{REFERENCES}

GreEn, G. E. (1967). Discussion of A new soil testing apparatus, by Ko, H. Y. \& Scott, R. F. Géotechnique 17 , No. 3,295 .

KJELLMAN, W. (1936). Report on an apparatus for consummate investigation of the mechanical properties of soils. Proceedings 1st Int. Conf. Soil Mech. 2, 16, 16-21.

Timoshenko, S. \& Goodier, J. N. (1951). Theory of elasticity. Second Edition, pp. 107-108. New York: McGraw-Hill.

J. M. Bell, Department of Civil Engineering, Colorado State University, 30 November, 1967.

Ko and Scott recently described a new triaxial soil testing device using an approximately cubical sample stressed on all six sides by water filled pressurized rubber bags. The differentially pressurized rubber bags are separated by a frame of rigid vanes. Stress-strain curves were given for Ottawa Sand.

In his letter, Green (1967) pointed out the large disparity of these results from those for the conventional triaxial test and suggested that interference of the rigid spacing frame with the sample causes additional stresses.

A modified version of this apparatus has been built and is in use at University College London. The modifications lead to results close to those of the conventional triaxial test. 


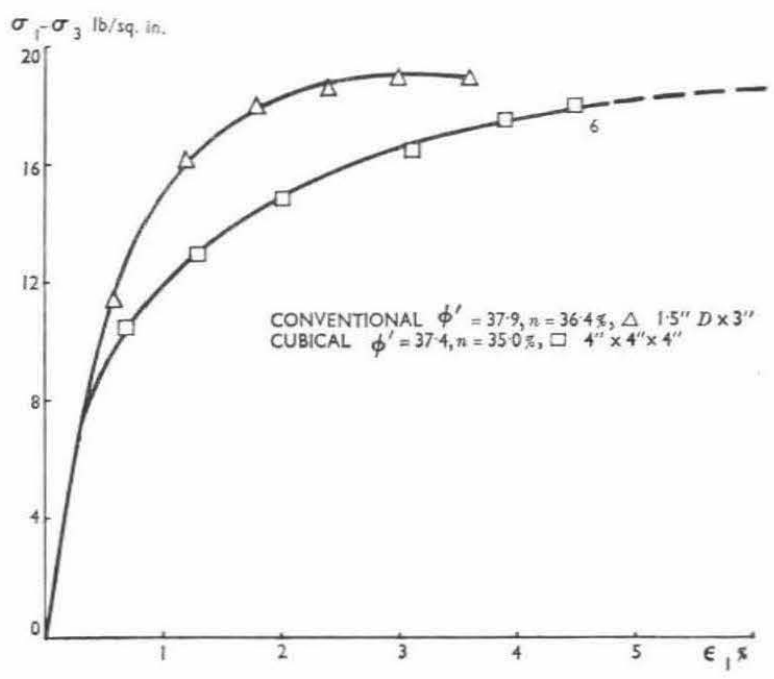

Fig. 1

The cubical sand sample is prepared in a separate rubber membrane and mould to give a high degree of control over the sample shape. Then the sample is subjected to a negative pore pressure and transferred to the soil test box where it is tested. The side vanes have been relieved so that the sample does not come into contact with them at any stage of testing.

Internal strain measurements carried out by the X-ray/lead shot technique (Roscoe, Arthur \& James, 1963) showed that sample contact with any of the rigid side vanes caused considerable strain distortion.

Figure 1 shows typical curves and other data for the conventional and cubical triaxial tests. Both samples were prepared by the same pouring technique and tested in drained triaxial compression, $\sigma_{3}^{\prime}$ being held constant at the same value in each test. The major principal strain distribution on a mid section of the cubical sample for point 6 in Fig. 1 gave an average of $4.54 \%$ over 85 elements with a standard deviation of 1.06 . There was no apparent pattern in the variations of strain. It is possible that the difference between the stress-strain curves shown in Fig. 1 is due mainly to an under-estimate of the maximum strain in the triaxial cell test, because, in this case, the strain was calculated in the conventional way from the relative movement of the end plattens.

\section{REFERENCES}

Green, G. E. (1967). Correspondence on A new soil testing apparatus, by Ko, H. Y. \& Scott, R. F. Géotechnique 17, No. 3, 295.

RosCoE, K. H., ARTHUR, J. R. F. \& JAMES, R. G. (1963). The determination of strains in soils by an X-ray method. Civ. Engng Pub. Whs Rev., July and August, 1963.

J. R. F. Arthur and B. K. Menzies, Department of Civil and Municipal Engineering, University College London, 12 February, 1968. 
In reply to the correspondence by Green (1967), the Authors wish to emphasize that the research programme in which the new soil test box was developed was aimed primarily at obtaining the stress-strain relations of soils and not at defining a failure surface, although some information on one form of the latter has also been obtained and is reported in a Paper by Ko \& Scott (1968), in which failure itself is also defined and discussed.

It was considered necessary, from the point of view both of determining constitutive relations and failure behaviour of a soil, to carry out tests at constant hydrostatic stress. To the Authors, this seems to be an essential feature of any soil testing arrangement.

The Authors feel that the doubt raised by Green concerning the rigid spacing frame interfering with the transmission of stresses from the water across the rubber membrane onto the soil sample is ill-founded and may be based on a misunderstanding of the functioning of the apparatus. The purpose of the spacing frame, shown in Fig. 4 of the original Paper, is to separate adjacent rubber membranes so that, when these membranes carry different pressure, the one with a higher pressure will not bulge into the other with a smaller pressure and thus give erroneous readings of the changes in volumes of water in the spaces behind the membranes (see Fig. 2 of original Paper). The members of the spacing frame are only $\frac{1}{2}$ in. wide and, as Green pointed out, at least half of this width is in contact with the rubber membranes, the remainder being in contact with the soil. However, a very large portion of each face of the cubical soil sample, measuring approximately 4 in. by 4 in. is still in contact with the flexible rubber membrane. Only a very narrow strip of each face along the edges of the sample is in contact with the spacing frame and therefore not subjected to the stress applied by the rubber membrane. Therefore, although a completely homogeneous stress state is not attainable due to the fact that allowance has to be made for the membranes to move as the sample deforms, yet over the bulk of the soil sample the stresses are known and equal to the pressures applied to the water in the spaces behind the membranes. The Authors believe that the measured uniformity in deformations on each face of the sample, confirms that the apparatus gives a good measurement of the stress-strain relation of the soil being tested.

The difference in behaviour of the Ottawa sand tested in the new apparatus and in the conventional triaxial apparatus or in plane strain devices of design similar to triaxial apparatus is believed by the Authors to be due, to a large extent, to the inhomogeneous (and therefore unknown) stress conditions in the triaxial test specimen. This inhomogeneity develops from the difference in rigidities of the specimen and the loading plates, and from the friction between them, as analysed by Haythornthwaite (1960) and Balla (1960). Even without these two undesirable effects in the triaxial compression test, the stress condition in the specimen is only one of radial symmetry, with the axial stress being the major principal stress and the radial stress being the minor principal stress. But the intermediate principal (tangential) stress is unknown, its value depending on the material properties of the specimen, which, however, is under investigation. Therefore, it is impossible to compare the results from the triaxial test over the complete range of stresses for one specimen with those from the soil test box which is believed to apply more homogeneous and, what is equally important, known stresses to the soil sample. However, at the start of a conventional triaxial shear test proceeding from a hydrostatic stress state, the minor and intermediate principal stresses are equal, and the end friction and rigid end plate effects are relatively less important. Hence, the results obtained during the initial stages of the conventional test can be validly compared with those from the soil test box, and indeed a good comparison was obtained as shown in Fig. 13 of the original Paper. As the test develops, the intermediate principal stress begins to differ from the minor principal stress and takes on an unknown value, and the rigid end plates and end friction constrain the sample to deform in the middle portion away from the ends. Eventually, failure zones develop in the sample so that most of the deformation takes place in these regions. 
In other words, the stress and the strain states in the triaxial specimen are both nonuniform and unknown beyond the initial stages of the test, and therefore the stress-strain relationship measured is difficult to interpret and is not directly comparable to that obtained in the soil test box which maintains a uniform stress and uniform strain state throughout the test up to strains of a few per cent. When the strains in the soil in the box become larger, the adjacent membranes would protrude beyond the spacing frame so as to interfere with one another, and the sample would undergo uneven deformation. All the tests reported by Ko \& Scott $(1967 \mathrm{a}, 1967 \mathrm{~b}, 1967 \mathrm{c})$ developed maximum strains below the levels where interference of membranes began, and in none of these tests was a 'peak' behaviour observed in the stressstrain plot. Whether such a peak does occur when the soil is allowed to deform continuously without membrane interference in the box remains to be investigated and will receive attention from the Authors in their future work with the soil test box.

Although a great number of tests have been carried out on the conventional triaxial apparatus and reported in the literature, the Authors suggest that caution should be used in employing such test results as a standard of comparison for the stress-strain behaviour of soils as determined in other equipment. The Authors have also found it difficult to accept that some of the judgement and intuition developed by triaxial test experience might be misleading. It was one function of the investigation utilizing the test box and described by the above series of papers to explore the extent to which previous experience might be inadequate.

\section{REFERENCES}

BAllA, A. (1960). Stress conditions in triaxial compression. J. Soil Mech. Fdns Div. Am. Soc. civ. Engrs 86, SM6, 57-84.

Green, G. E. Correspondence on A new soil testing apparatus, by Ko, H. Y. \& Scott, R. F. Géotechnique 17, No. 3, 295 .

Haythornthwaite, R. M. (1960). Mechanics of the triaxial test for soils. J. Soil Mech. Fdns Div. Proc. Am. Soc. civ. Engrs 86, SM5, 35-62.

Ko, H. Y. \& Scort, R. F. (1967a). A new soil testing apparatus. Géotechnique 17, No. 1, 40-57.

Ko, H. Y. \& Scotr, R. F. (1967b). Deformation of sand in hydrostatic compression. J. Soil Mech. Fdns Div. Proc. Am. Soc. civ. Engrs 93, SM3, 137-156.

Ko, H. Y. \& Scotr, R. F. (1967c). Deformation of sand in shear. J. Soil Mech. Fdns Div. Proc. Am. Soc. civ. Engrs 93, SM5, 283-310.

Ko, H. Y. \& Scort, R. F. (1968). Deformation of sand at failure. J. Soil Mech. Fdns Div. Proc. Am. Soc. civ. Engrs. To be published.

H. Y. Ko,
Department of Civil Engineering,
University of Colorado,
and
R. F. Scott,
Division of Engineering and Applied Science,
California Institute of Technology,
29 January, 1968.

\section{STEREOGRAPHIC REPRESENTATION OF JOINT SURVEYS}

(Price, D. G. \& Knill, J. L., Géotechnique 17, No. 4, 411-432)

While agreeing with the Authors that upper hemisphere projection is best suited to joint surveys, it would be of interest to know if the stereograms are based on a polar equal area stereographic net, since this net has the effect of grouping steeply dipping joints closer together, thereby artificially increasing the density of poles around the periphery of the stereogram. 
It is considered that too small a contour interval often gives irregular contours which tend to mask the overall pattern of joint systems, whereas a larger contour interval of perhaps $2 \%$ might provide a clearer picture. Joint poles falling outside the $2 \%$ contour can be denoted by points and this enables any particularly dangerous joints to be recognized quickly. It appears that the stereogram contours in the Paper have been drawn using a circle of unit area to build up a pattern of densities on a grid system and the contours interpolated between grid points. More regular contours can usually be obtained by using the counting circle throughout. The entry points of contours into a stereogram should be diametrically opposite the exit points of the same contours on the other side of the stereogram. This can be achieved with a special counting device described by Phillips (1959).

These points may be regarded at first as rather academic but the joints which generally control slope stability fall towards the outside of the stereogram, consequently it is important to obtain as much accuracy and clarity in this region as possible.

\section{REFERENCE}

PHILlips, F. C. (1959). The use of stereographic projection in structural geology. Edward Arnold.

K. M. Pare, Pre-Piling Surveys Ltd, Peterborough, 8 January, 1968.

\section{SOME RESULTS CONCERNING DISPLACEMENTS AND STRESSES IN A NON-HOMOGENEOUS ELASTIC HALF-SPACE}

(Grison, R. E., Géotechnique 17, No. 1, 58-67)

A number of correspondents have kindly drawn attention to errors in this Paper and have also requested further detailed information concerning the case when the load is uniformly applied at the ground surface over a circular area.

The errata are:

(i) A factor $(1+\xi z)$ is missing from the integrands both of equations (17) and (23).

(ii) In equation (41), and in the last equation on p. 66 which is derived from it, the kernel

$$
K=\frac{2}{\pi} \frac{\sin (b \xi) \sin (x \xi)}{\xi}
$$

The kernel quoted in the text of the Paper remains correct for equations (39) and (40).

(iii) $f$ should be replaced by $\bar{f}$ in equation (33).

(iv) Expression (29) should equal zero.

The passage from the plane strain solution, derived in detail in the Paper, to the axisymmetrical case is not quite so straightforward as I suggested on p. 63 and again on p. 67. To avoid any possibility of misunderstanding I give below, in the notation of the Paper, for the axi-symmetrical case, expressions for the radial and vertical displacements $u$ and $w$ and those components of stress usually required:

$u(r, z)=\frac{q b}{4 m} \int_{0}^{\infty} \frac{J_{1}(r \xi) J_{1}(b \xi)}{\Lambda \xi \beta} e^{-\xi z}[\xi \beta F(\xi \beta)+1+\xi \beta F(\xi y)+2 \xi \beta \log (\xi y)] d \xi$ 


$$
\begin{aligned}
& w(r, z)=\frac{q b}{4 m} \int_{0}^{\infty} \frac{J_{0}(r \xi) J_{1}(b \xi)}{\Lambda \xi \beta} e^{-\xi z}[1+\xi \beta F(\xi \beta)-\xi \beta F(\xi y)] d \xi \\
& -\frac{\sigma_{z z}}{q}=\frac{1}{2} \int_{0}^{\infty} \frac{b J_{0}(r \xi) J_{1}(b \xi)}{\Lambda} e^{-\xi z}\{\xi y[F(\xi y)+F(\xi \beta)]-[F(\xi y)-F(\xi \beta)]+2 \xi y \log (\xi y) \\
& +1+(1+\xi y) / \xi \beta\} d \xi \\
& -\frac{\sigma_{r r}}{q}=\frac{1}{2} \int_{0}^{\infty} \frac{b J_{0}(r \xi) J_{1}(b \xi)}{\Lambda} e^{-\xi z}\left\{\left[F(\xi \beta)-F(\xi y)+1+\frac{1}{\xi \beta}\right]-\xi y\left[1-\frac{J_{1}(r \xi)}{r \xi J_{0}(r \xi)}\right][F(\xi \beta)\right. \\
& \left.\left.+F(\xi y)+\frac{1}{\xi \beta}+2 \log (\xi y)\right]\right\} d \xi \\
& -\frac{\sigma_{\tau z}}{q}=\frac{1}{2} \int_{0}^{\infty} \frac{b J_{1}(r \xi) J_{1}(b \xi)}{\Lambda} e^{-\xi z}\left\{\frac{z}{\beta}-\xi y[F(\xi y)-F(\xi \beta)]\right\} d \xi .
\end{aligned}
$$

If the hoop stress $\sigma_{\theta \theta}$ is needed this is most readily found from the equation of radial equilibrium:

$$
\frac{\partial \sigma_{r r}}{\partial r}+\frac{\partial \sigma_{r z}}{\partial z}+\frac{1}{r}\left(\sigma_{r r}-\sigma_{\theta \theta}\right)=0 .
$$

The above amendments and additions affect in no way the Paper's basic conclusion that a semi-infinite incompressible elastic medium whose shear modulus increases linearly with depth from zero at the surface ( $\beta=0$ in the above equations), responds to any vertical surface loading exactly like a Winkler spring model: namely, the settlement at any point of the surface is directly proportional to the intensity of vertical stress there.

R. E. Gibson, King's College, University of London, 24 January, 1968.

\section{APPLICATION OF ELECTRO-OSMOSIS TO A FOUNDATION PROBLEM IN A NORWEGIAN QUICK CLAY}

(Bjerrum, L., Moum, J. \& Eide, O., Géotechnique 17, No. 3, 214-235)

In every field application of electro-osmotic drainage, the rate of consolidation is of considerable importance. A simple theory for the rate of consolidation in the presence of an electric field is presented here and the predicted rate of settlement is compared with the data presented by the Authors. The theory leads to the important conclusion that the rate of soil consolidation in the presence of an electric field is governed by the Terzaghi coefficient of consolidation, that is, depends upon the compressibility and hydraulic permeability of the soil, and does not depend upon the electro-kinetic permeability of the material. If correct, the theory also has some important implications for the evaluation of the economic feasibility of an electro-osmotic installation.

In the field installation reported on by the Authors, a large number of closely spaced solid rods were used as electrodes. As a first approximation, this system can be considered to be one of electro-osmosis between two parallel plates in the presence of a uniform field. As the electric current pumped water towards the negative electrodes (cathode), first a positive pore pressure had to develop until the seal between the soil and the electrode was broken and water could be ejected from the soil. As no fluid was added at the anodes, ejection of water had to produce soil consolidation. When the pore water pressure gradients became equal and opposite 
to the voltage gradients throughout the system, consolidation was complete. Thus, consolidation in an electric field involves combined electrically and hydraulically induced flow. Considering only one dimensional flow between parallel plates in an electric field that is sensibly constant with time, the differential equation governing consolidation can be written as:

where

$$
k_{\mathrm{e}} \frac{\partial^{2} V}{\partial x^{2}}+\frac{k}{\gamma_{\mathrm{w}}} \frac{\partial^{2} u}{\partial x^{2}}=m_{\mathrm{\vee}} \frac{\partial u}{\partial t} \quad \text {. . . . . . . . . }
$$

$k_{\mathrm{e}}$ is the coefficient of electrokinetic permeability

$k$ is the coefficient of hydraulic permeability

$V$ is the applied voltage

$u$ is the resulting pore water pressure

$m_{\mathrm{v}}$ is the coefficient of volume compressibility of the soil and

$t$ is time

Dividing equation (1) by $k / \gamma_{\mathrm{w}}$ and introducing the dummy variable

$$
\xi=\frac{k_{\mathrm{e}}}{k} \gamma_{\mathrm{w}} V+u \quad \text {. . . . . . . . . . . }
$$

leads to the familiar diffusion equation

$$
c_{\mathrm{v}} \frac{\partial^{2} \xi}{\partial x^{2}}=\frac{\partial \xi}{\partial t} \quad \text {. . . . . . . . . . . . }
$$

in which $c_{\mathrm{v}}=k \gamma_{\mathrm{w}} / m_{\mathrm{v}}$ and is defined as the coefficient of consolidation of the soil.

The boundary conditions are:

$$
\begin{aligned}
\text { cathode: } x & =0, t=0, \xi=0 \\
\text { anode }: x & =L, t=t, \partial \xi / \partial x=0 \\
\text { initial } x & =x, t=0, \xi=\left(k_{\mathrm{e}} / k\right) \gamma_{\mathrm{w}} V
\end{aligned}
$$

The solution to equation (3) for these boundary conditions is the well-known solution for soil with an initially triangular pore pressure distribution and is readily available elsewhere (e.g. Leonards, 1962).

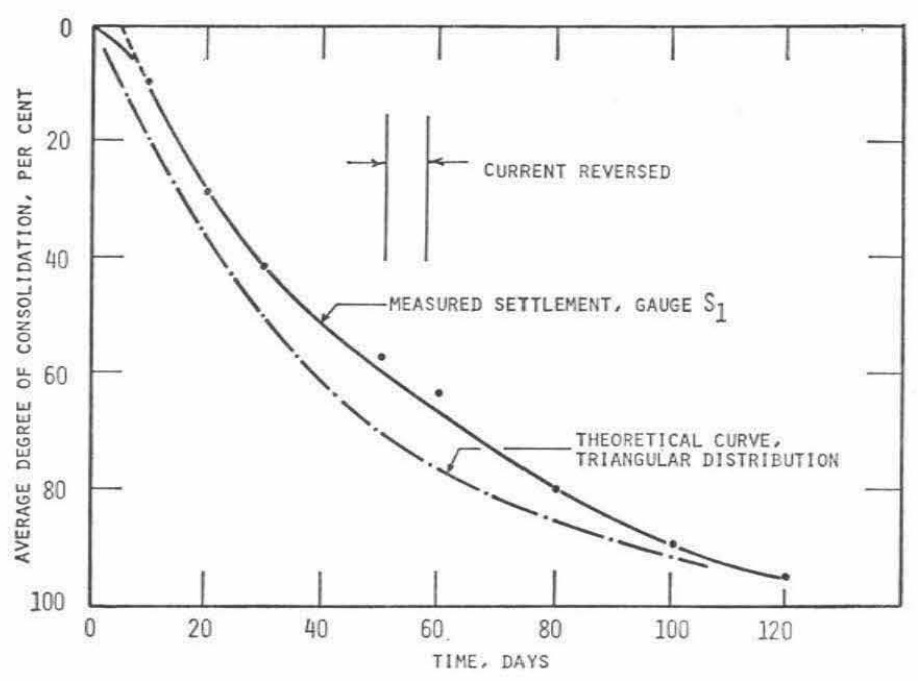

Fig. 1 
As the Authors have provided a value for the coefficient of consolidation of the soil, a theoretical time curve can be plotted as shown in Fig. 1. The theoretical curve suggests that after 120 days of treatment the soil should have achieved $95 \%$ consolidation. The field settlement data suggest that this is approximately correct and therefore, the field curve shown in Fig. 1 was developed on the assumption that the $50 \mathrm{~cm}$ of settlement recorded at plate $\mathrm{S}-1$ was $95 \%$ of the total settlement.

The agreement between the measured and theoretical curves in Fig. 1 is considered quite good with the slower initial consolidation that was found in the field ascribed to the time required to develop positive pore water pressures at the cathode so that free drainage could occur. Therefore, the Writer concludes that the rate of soil consolidation in an electro-osmotic installation is predictable, within engineering limits, through use of the theory of consolidation.

\section{REFERENCE}

Leonards, G. A. (1962). Foundation Engineering, pp. 164-165. McGraw-Hill.

M. I. Esrig,

Department of Geotechnical Engineering, Cornell University, 2 February, 1968.

\section{RESIDUAL SOILS OF THE KUMASI DISTRICT IN GHANA}

(Ruddock, E. C., Géotechnique 17, No. 4, 359-377)

The Author states that Fig. 7(b) ‘... shows that the linear shrinkage gives at least a rough indication of the property of plasticity as understood in soil engineering'. The mean relationship plotted in Fig. 7(b) for decomposed phyllite appears to be:

$$
\mathrm{PI}=4 \cdot 3 \mathrm{LS}-21 \cdot 5
$$

where the values plotted are those for PI's in excess of about 15 .

The following notes on the above and similar relationships may be of interest.

When there was any doubt as to the reliability of the PI obtained by normal testing methods, designers in some parts of Africa used to check such values with that given by the relationship

$$
\mathrm{PI}=3 \mathrm{LS}
$$

where there was considered to be little difficulty in obtaining an acceptably accurate value for the lineal shrinkage.

A relationship similar to (1) had been determined in Australia (County Roads Board, 1951) from test data and took the form

or

$$
\begin{aligned}
\mathrm{LS} & =1 \cdot 6+0 \cdot 312 \mathrm{PI} \\
\mathrm{PI} & =3 \cdot 2 \mathrm{LS}-5 \cdot 1
\end{aligned}
$$

Confronted with the difficulty in obtaining acceptable values of the PI for Kenya lateritic soils after stabilization, during the design for a development project in 1960 , the Writer investigated the background for relationship (2).

Extending the line of thought followed during his production of the 'missing control' for mechanical stabilization (Wooltorton, 1947, 1966), he obtained, for fine grained soil material, the background relationship of:

$$
\begin{aligned}
\frac{C_{\mathrm{f}}}{100} & =\frac{\text { shrinkage in cc/100 gm (between LL and SL) }}{\text { dry volume in cc/100 gm }} \\
& =\frac{(\mathrm{PI}+\overline{\mathrm{PL}-\mathrm{SL})}}{\text { dry volume in cc } / 100 \mathrm{gm}}
\end{aligned}
$$


or

$$
C_{\mathrm{f}}=d(\mathrm{PI}+\overline{\mathrm{PL}-\mathrm{SL}})
$$

where $C_{f}$ is the volume change when a remoulded powdered soil is dried from the LL to the SL and $d$ is the apparent specific gravity of the dried soil.

From definition, LS may be expressed in terms of $C_{f}$ by

$$
\mathrm{LS}=100\left(1-\sqrt[3]{\frac{100}{100+C_{1}}}\right) \quad . \quad . \quad . \quad . \quad .
$$

assuming that a cubical block of the remoulded soil will shrink by an equal amount relative to each of the axes.

A first approximation of (5) applicable to low plasticity soils with a LS of not greater than about 7 is

$$
C_{\mathrm{f}}=3 \mathrm{LS}
$$

For such materials (PL-SL) is small and may be neglected, when

or

$$
\begin{aligned}
d \mathrm{PI} & \approx 3 \mathrm{LS} \\
\mathrm{PI} & =3 \mathrm{LS} / d
\end{aligned}
$$

From shrinkage test data for Kenya soils

or

$$
\begin{aligned}
d & =1.59 \\
\mathrm{PI} & =1.9 \mathrm{LS}
\end{aligned}
$$

For more active or more apparently active soils

(i) (PL-SL) cannot be neglected

(ii) $C_{\mathrm{f}}$ is no longer representable by $3 \mathrm{LS}$ as an acceptable approximation. For $C_{\mathrm{f}}$ values of the order of $40 \%$, a more acceptable approximation is

$$
4 \cdot 68 \mathrm{LS}=C_{\mathrm{f}}+10
$$

Substituting (8) in (4) gives

$$
d(\mathrm{PI}+\overline{\mathrm{PL}-\mathrm{SL}})=(4 \cdot 68 \mathrm{LS}-10)
$$

For Kenya halloysite red soils (PL-SL) is, from limited data, about 16, when $\mathrm{PI}=2 \cdot 94 \mathrm{LS}-22 \cdot 3$.

This relationship assumes that the LL and PL values determined by normal testing are absolute. A characteristic of Kenya clay minerals is, however, that they contain, on the average, about $7 \%$ of water (with extreme values of about $13 \%$ ) which does not enter into any volume change relationship and is only lost at moisture contents below the SL. The value given to (PL-SL) should thus, it is considered, be reduced by about $7 \%$ if the test values for the PI are to be used in any volume change correlationship.

Table 1

\begin{tabular}{l|r|r|r|r}
\hline & LS & PI & LS & PI \\
\hline Ghana, formula (1) & 7 & 9 & 15 & 43 \\
\hline Australia, formula (3) & 7 & 17 & 15 & 43 \\
\hline Kenya, formula (9) & 7 & 6 & 15 & 29 \\
\hline Kenya, formula (10) & 7 & 11 & 15 & 35 \\
\hline
\end{tabular}


The modified theoretical formula thus becomes

$$
\mathrm{PI}=2 \cdot 94 \mathrm{LS}-15 \cdot 3
$$

A plot of the LS and PI values for such soils gave the mean relationship of

$$
\mathrm{PI}=3 \cdot 06 \mathrm{LS}-10 \cdot 8
$$

The application of the above formulae within the range of $C_{\mathrm{f}}=22 \%$ to $C_{\mathrm{f}}=60 \%$ is compared in Table 1.

\section{REFERENCES}

COUnty ROAds BOARD, Melbourne N.3 (1951). The relation between linear shrinkage and other simple tests for average soils. Research Memo. No. 7.

Wooltorton, F. L. D. (1947). Relation between the plastic index and the percentage of fines in granular soil stabilisation. Proc. 27th An. Mtg. Highway Research Board.

Wooltorton, F. L. D. (1966). Aggregates for road construction. Letter to Editor. Roads and Road Construction 44, No. 528, December.

F. L. D. Wooltorton, Howard Humphreys \& Sons, Epsom, Surrey, 22 February, 1968.

\section{BOOK REVIEW}

El Penetrómetro y el reconocimiento de los suelos. Ministerio de Obras Publicas, Madrid, 1967.

The well-known book by Monsieur G. Sanglerat entitled 'Le Pénétromètre et la reconnaissance des sols' has been translated into Spanish by G. de Navacerrada, and the opportunity has been taken of making several revisions and additions. 